\title{
Prominent Burst Firing of Dopaminergic Neurons in the Ventral Tegmental Area during Paradoxical Sleep
}

\author{
Lionel Dahan*, ${ }^{*, 2}$, Bernadette Astier', Nicolas Vautrelle', Nadia Urbain', Bernat Kocsis² and Guy Chouvet' \\ 'Laboratoire de Neuropharmacologie et Neurochimie, Université Lyon I, Lyon, France; '2Department of Psychiatry, Harvard Medical School, \\ Boston, MA, USA
}

\begin{abstract}
Dopamine is involved in motivation, memory, and reward processing. However, it is not clear whether the activity of dopamine neurons is related or not to vigilance states. Using unit recordings in unanesthetized head restrained rats we measured the firing pattern of dopamine neurons of the ventral tegmental area across the sleep-wake cycle. We found these cells were activated during paradoxical sleep (PS) via a clear switch to a prominent bursting pattern, which is known to induce large synaptic dopamine release. This activation during PS was similar to the activity measured during the consumption of palatable food. Thus, as it does during waking in response to novelty and reward, dopamine could modulate brain plasticity and thus participate in memory consolidation during PS. By challenging the traditional view that dopamine is the only aminergic group not involved in sleep physiology, this study provides an alternative perspective that may be crucial for understanding the physiological function of PS and dream mentation.

Neuropsychopharmacology (2007) 32, I232-124I. doi: I0.1038/sj.npp. I30 I25I; published online 6 December 2006
\end{abstract}

Keywords: dopamine; ventral tegmental area; bursts; sleep; paradoxical sleep; reward

\section{INTRODUCTION}

The dopaminergic mesocorticolimbic system is formed by dopamine neurons located in the ventral tegmental area (VTA), which project to the nucleus accumbens, prefrontal cortex, septum, amygdala, and hippocampus. There is a general agreement that midbrain dopamine neurons play key roles in unpredicted and novel reward processing, although possible activation of dopamine neurons by salient stimuli that are not rewarding is still debated (for review, see Ungless (2004)). Electrophysiological recordings from dopamine neurons in awake animals have demonstrated that these cells fire bursts of spikes in response to novel salient stimuli (Kiyatkin, 1995; Ljungberg et al, 1992; Steinfels et al, 1983). Electrochemical monitoring of extracellular dopamine concentration showed that this increase in bursting activity is accompanied by a transient increase in dopamine levels (Wightman and Robinson, 2002). When stimuli become familiar or predicted, their presentation fails to activate the dopamine cells (Ljungberg et al, 1992; Schultz et al, 1993) or to increase the dopamine levels (Kilpatrick et al, 2000), indicating that such activations depend on novelty but not on motor components of

*Correspondence: Current address: Dr L Dahan, Departement de Neurosciences Fondamentales, Centre Medical Universitaire, I, rue Michel Servet, I2II Geneve 4, Suisse, Tel: +4I (0) 2237954 37, Fax: + 4I (0) 2237954 52,

E-mail: Lionel.Dahan@medecine.unige.ch

Received 22 March 2006; revised and accepted 27 September 2006 the behavioral tasks. According to Lisman and Grace (2005), the activation of the dopamine system induced by novel salient stimuli required for memory consolidation is triggered by the hippocampus and the pedunculopontine tegmental nucleus (PPN). This hypothesis is based on the observation that novelty induced increase in extracellular dopamine levels was blocked by intrahippocampal infusion of TTX (Legault and Wise, 2001). The hippocampus is known to activate VTA dopamine cells via a polysynaptic pathway involving the activation of nucleus accumbens which in turn inhibits the ventral pallidum leading to disinhibition of dopamine cells (Floresco et al, 2003). The PPN, which sends direct excitatory inputs to the VTA (Omelchenko and Sesack, 2005; Omelchenko and Sesack, 2006), has been shown to be activated by salient stimuli and to participate in dopamine activation induced by salient events (Pan and Hyland, 2005).

In homeothermic animals, sleep is divided into two main distinct stages: slow wave sleep (SWS) and paradoxical sleep (PS). SWS is characterized by high-voltage slow oscillations in the electroencephalogram (EEG) associated with weak electromyographic (EMG) activity. During PS, activity in the forebrain is comparable to waking levels with pronounced and sustained theta rhythm in the hippocampus together with rapid eye movements (REM; PS is also called REM sleep) and a complete loss of muscle tone (Jouvet, 1967). During the past 50 years of sleep research, PS has been associated with various functions, ranging from corneal respiration (Fitt and Gonzalez, 2006) to dreaming (Aserinsky and Kleitman, 1953). It has been proposed 
recently that one possible function of PS is to participate in reconsolidation of newly acquired memories during sleep via off-line replay of previously experienced events (Ribeiro and Nicolelis, 2004; Stickgold et al, 2001; Stickgold and Walker, 2005). Indeed, in humans, imaging studies showed that cerebral regions activated during learning are reactivated again during PS following the task (Maquet et al, 2000; Peigneux et al, 2003). It has also been shown in rats that hippocampal ensemble activity recorded during spatial task is replayed during PS (Louie and Wilson, 2001). Furthermore, the amount of PS increased after spatial learning in the Morris water maze (Smith and Rose, 1997) and specific PS deprivation following such a task impaired following performances (Smith and Rose, 1996).

As the hippocampus is highly active during PS and since pharmacological activation of hippocampus increases the activity of dopamine neurons (Floresco et al, 2003; Lodge and Grace, 2006b), one would expect dopamine neurons to be activated during PS sleep. Such a hypothesis is further supported by the fact that PPN, which regulates dopamine cell bursting activity (Lodge and Grace, 2006a), is also strongly activated during PS (Datta and Siwek, 2002; El Mansari et al, 1989; Maloney et al, 1999; Verret et al, 2005). Until now, there have been few reports concerning the activity of dopamine cells during PS. On the one hand, c-fos expression is increased in dopamine cells during a rebound of PS (Maloney et al, 2002) and a recent microdialysis study demonstrated an increase in extracellular levels of dopamine in nucleus accumbens and prefrontal cortex during PS (Lena et al, 2005). On the other hand, early electrophysiological studies in rats and cats concluded that the firing rate of these neurons was unrelated to the sleep-wake cycle (Miller et al, 1983; Trulson and Preussler, 1984). As a result of these latter reports, dopamine neurons are generally viewed as the only aminergic neurons not affected by vigilance states (for review see Pace-Schott and Hobson (2002)). However, among the early electrophysiological studies, there is the suggestion of a possible modification of the firing pattern during PS since an increased variance of interspike intervals during PS was reported (Miller et al, 1983). Other studies only considered changes in the mean firing rate of dopamine neurons and overlooked any possible state-dependent shifts in the discharge pattern.

Dopamine neurons, in vivo, exhibit tonic irregular single spike firing interrupted by bursts of spikes often with decreasing spike amplitude followed by brief silences (Grace and Bunney, 1983) and it has been shown that the mean firing rate and the bursting pattern of dopamine neurons can be modulated independently (Floresco et al, 2003). A state-dependent shift in discharge pattern might be crucial since burst firing of dopamine neurons was shown to result in a much larger synaptic dopamine accumulation than single spike firing (Floresco et al, 2003; Gonon, 1988; Venton et al, 2003).

To test the hypothesis that mesolimbic dopamine neurons are activated during PS, we examined their activity across vigilance states with special attention to possible changes in the pattern of firing. In order to compare bursting activity of dopamine cells across sleep-wake cycle and bursting activity during a well-documented activation of dopamine system, we performed recordings during the consumption of palatable food. This condition is known to increase extracellular levels of dopamine (Bassareo and Di Chiara, 1997; Westerink et al, 1997) with kinetics suggesting sustained burst firing of VTA dopamine neurons (Roitman et al, 2004).

\section{MATERIALS AND METHODS}

All procedures were approved by the Claude Bernard University ethical committee in accordance with the corresponding European Communities Council Directives (86/609/EEC). They also met international standards and were previously described in detail (Souliere et al, 2000; Urbain et al, 2000). Experiments were performed during the light part of the $12 / 12 \mathrm{~h} \mathrm{light/dark}$ cycle. Twelve male Sprague-Dawley rats (Charles River, l'Arbresle, France) weighing 280-350 g were deeply anesthetized (chloral hydrate $400 \mathrm{mg} / 10 \mathrm{ml}$ freshly diluted in $\mathrm{NaCl}$, priming injection: $400 \mathrm{mg} / \mathrm{kg}$ i.p., supplemented by perfusion: $120 \mathrm{mg} /$ $\mathrm{kg} / \mathrm{h}$ i.p.). They were mounted in a classical stereotaxic frame with conventional ear and incisors bars. Temperature was maintained at $37^{\circ} \mathrm{C}$ with a regulated electric heating pad (Harvard Apparatus). Three small stainless-steel screws were turned into small holes bored into parietal and frontal or occipital parts of the skull in order to monitor bipolar EEG. Three steel wires were inserted into the neck muscles in order to record the electromyogram (EMG). A liquid bonding resin (Superbond, Sun Medical, Japan) was then applied on the skull surface to enhance binding of the dental cement, except above the reference point (lambda) needed for positioning further stereotaxic tracks. A U-shaped aluminum piece, fixed to a flexible carriage (GFG Co., Pierre-Benite, France) fastened to the stereotaxic apparatus, was positioned above the VTA and lambda suture. This U-piece was then embedded in dental cement with the EEG screws and EMG wires and their six-pin connector, as already described (Souliere et al, 2000; Urbain et al, 2000, 2002, 2004, 2006), leaving a well inside the U-piece. At the end of the surgery, the well was closed with bone wax and wound-healing cream (Madecassol, Serdex, France) was poured out on all the borders of the implant to facilitate healing. The rat was then removed from the stereotaxic apparatus and placed in his individual home cage. The U-shaped piece (about $5 \mathrm{~g}$ weight) was well tolerated by the rats, which were able to move, sleep, feed, and drink normally in their home cage.

After 2 days of recovery, animals were progressively habituated to the head fixation procedure (8-12 days). Their head was painlessly secured to the stereotaxic frame by screwing the U-shaped piece, cemented to the rat's head, with its associated carriage; their body lying comfortably in a hammock. This procedure allowed forelimb movements thereby enabling the animals to groom and grasp food when offered by the experimenter. At the end of the training period, the rats stayed calm for a period of 5-6h during which quiet wakefulness, SWS, as well as PS episodes were typically observed. After training, rats were again anesthetized (chloral hydrate $400 \mathrm{mg} / 10 \mathrm{ml}$ freshly diluted in $\mathrm{NaCl}$, $320 \mathrm{mg} / \mathrm{kg}$ i.p., supplemented as needed. Lidocaine was applied locally on the dura mater just before its dissection) and the skull and dura matter were removed. To prevent any infection, an antibiotic solution (neomycin trisulfate 
hydrate, Fluka) was laid on the skull inside the well, which was then closed with bone wax. This wound dressing was replaced every day.

After habituation, daily recording sessions were typically performed over a maximum of 7-10 days, each session lasting about $4-6 \mathrm{~h}$. Extracellular recordings of VTA neurons $(-5.3$ to $-6.0 \mathrm{~mm}$ posterior, $0.5-0.9 \mathrm{~mm}$ lateral and $7.4-8.6 \mathrm{~mm}$ ventral to bregma) were performed using glass micropipettes (broken back to an external tip diameter of $2-3 \mu \mathrm{m}$, impedance of $6-12 \mathrm{M} \Omega$ at $10 \mathrm{~Hz}$ ) filled with $2 \%$ Pontamine Sky Blue in 0.5 M sodium acetate ( $\mathrm{pH}$ 7.5). The electrode signal was filtered and amplified $(0.2-10 \mathrm{kHz}$; P16, Grass Instruments, West Warvick, USA), fed to a $50 \mathrm{~Hz}$ noise eliminator (Hum-Bug, Quest Scientific, Vancouver, Canada) and filtered again $(1-3 \mathrm{kHz} ; 5 \mathrm{~A} 22 \mathrm{~N}$ differential amplifier, Tektronix Co). Single-unit activity (signalto-noise ratio of at least 3:1) was isolated with an amplitude spike discriminator (CEMI, Lyon, France). Samplings of electrode signal (sampling rate $10 \mathrm{kHz}$ ), signal from the spike discriminator and polygraphic signals (EEG and EMG amplified using a P55 from Grass Instruments, sampling rate $256 \mathrm{~Hz}$ ) were collected on a personal computer via a CED interface (Cambridge Electronic Design, Cambridge, UK) using the Spike 2 software. After each recording session, the well was filled with saline solution $(\mathrm{NaCl} 0.9 \%)$ and covered with wax. At the end of the last recording session, the animals were killed and subsequent histological localization of the recording sites, labeled by iontophoretic deposit of Pontamine Sky Blue during the last three recording sessions, were made on cresyl violet-stained coronal sections.

The activity of some dopamine neurons was monitored during the entire period of consumption of a highly palatable food. Pieces of cake (Galettes Saint-Michel ${ }^{\mathbb{R}}$, France, $0.5-1 \mathrm{~g}$ ) were given by hand after at least $40 \mathrm{~s}$ of basal recording during quiet waking (no predictive cue was intentionally used). Rats were habituated to eat such pieces of cake in their home cages and in the restraining frame during the week preceding the recording sessions. Palatable food was always present in the experimental room in an open box so that the animals were habituated to the smell.

All spontaneously active neurons encountered within the VTA were recorded. To identify the different cell types, we computed average action potentials (at least 30 traces) for each cell and analyzed the shape of the waveform and the duration of action potentials (from the onset to the end). Dopamine neurons were identified by their long-duration triphasic action potentials, the distinction between short and long durations being determined a posteriori by the analysis of the repartition of action potential durations of all recorded VTA neurons (see Results).

Further analyses were conducted only on putative dopamine cells. Single unit discharge of dopamine neurons was analyzed off-line using Spike 2 analysis software. Burst detection was performed using a custom Spike 2 script based on the criteria of Grace and Bunney (1984), a burst beginning with the occurrence of two spikes with an interspike interval $<80 \mathrm{~ms}$, and ending with the occurrence of an interspike interval $>160 \mathrm{~ms}$. Mean firing, percentage of spikes fired in bursts, mean number of bursts per second, mean number of spikes per burst and intraburst firing rate of individual cells were calculated in each vigilance state recorded during at least $20 \mathrm{~s}$. Correlations to EEG rhythm were assessed by computing spike triggered averaging of the EEG signal. The same method was used to analyze the firing and burst activity before and during the palatable food consumption. ANOVA, followed by Tukey-Kramer post hoc pair-wise comparisons, were employed to determine if discharge rate and bursting parameters varied as a function of vigilance stages. Student's $t$-test for paired values was used to compare activity before and during eating palatable food and the activity at different times relatively to PS onset and offset. The significance level was set at $p<0.05$ for all statistical analyses. All data are expressed as mean \pm SEM.

\section{RESULTS}

\section{Characterization of Dopamine Neurons}

One hundred twenty-two neurons were recorded within the VTA of 12 rats (see recording sites location Figure 1c). An analysis of the total length of action potentials of all recorded neurons (Figure 1b) divided the population into 3 groups. Twelve neurons exhibited short biphasic action potentials, the others had short $(n=16)$ or long $(n=94)$
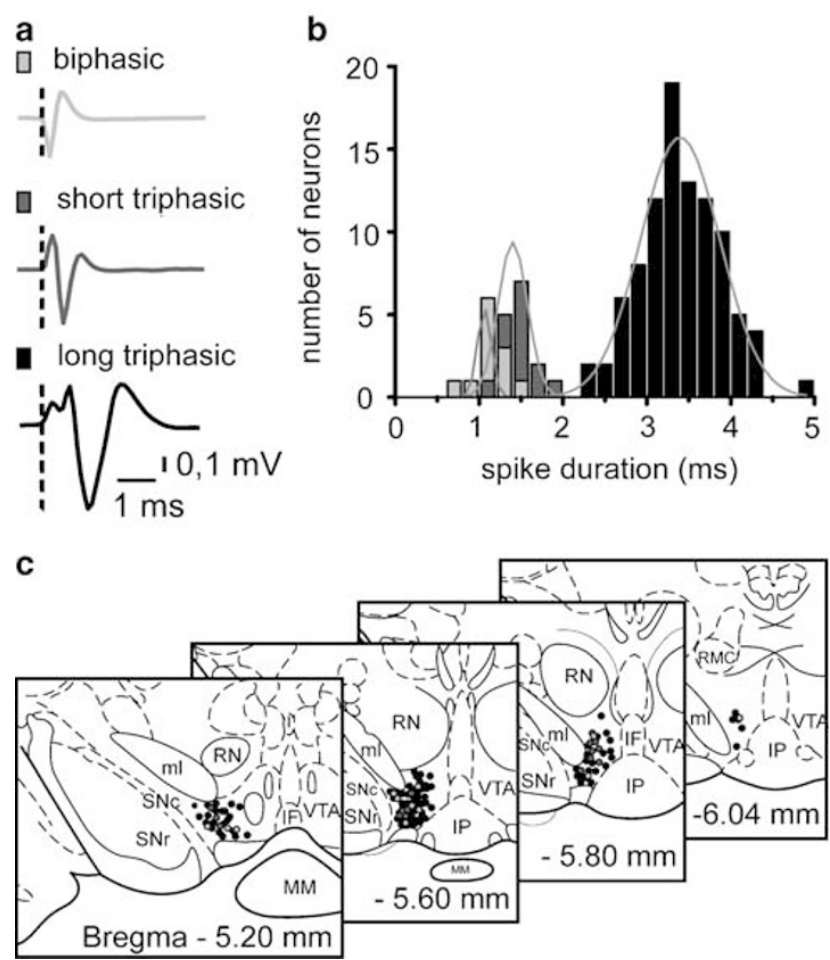

Figure I Electrophysiological characterization of three neuronal populations within the VTA. (a) Typical examples of short bisphasic, short triphasic, and long triphasic average extracellular waveforms. (b) Distribution of spike duration of all recorded neurons. Note clear separation of the group of long spikes on the trimodal histogram. A triple-Gaussian fit $\left(r^{2}>0.9\right)$ confirms the $>2 \mathrm{~ms}$ criterion for broad triphasic neurons. (c) Mapping of recording sites within the VTA. Neurons with biphasic, short triphasics, and long triphasic waveforms are represented by light gray, dark gray, and black bars and dots, respectively. IF: interfascicular nucleus, IP: interpeduncular nucleus, ml: medial lemniscus, MM: medial mammillary nucleus, RN: red nucleus, SNc/SNr: substantia nigra pars compacta and recticulata, VTA: ventral tegmental area. 


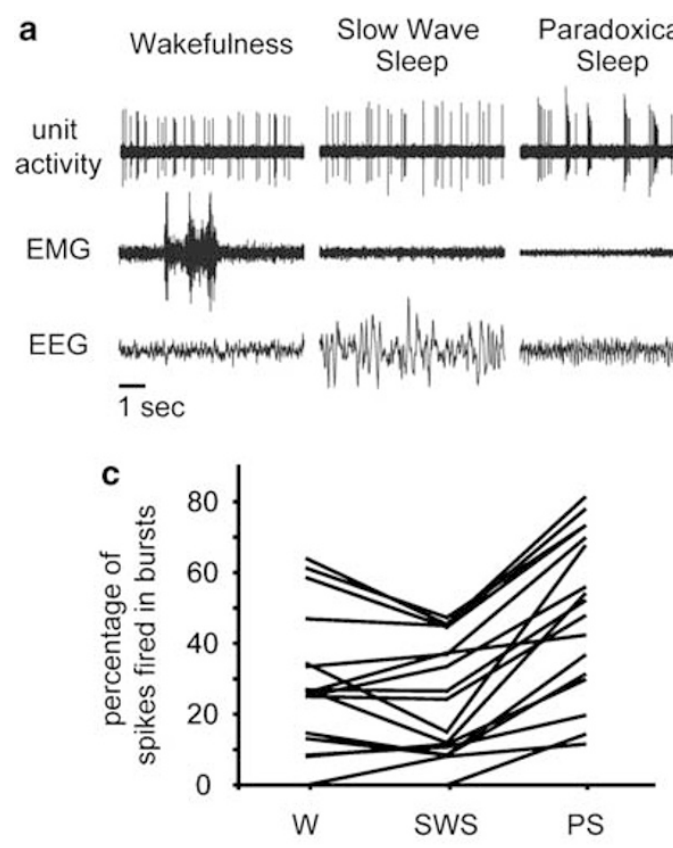

b $\quad \begin{array}{cc}\text { prior to } & \text { during } \\ \text { feeding } & \text { feeding }\end{array}$

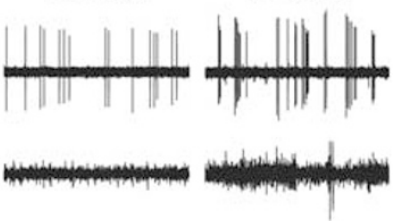

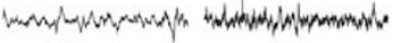

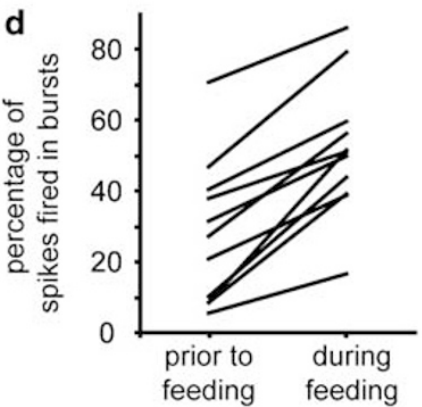

Figure 2 Dopamine neurons switch to a bursting mode during PS and palatable food consumption. (a, b) Shows examples of spike firing pattern (top traces) of two dopamine neurons, one (a) recorded during the three vigilance states and the other (b) recorded before and during palatable food consumption. Sleep wake cycle was monitored by EMG (middle traces) and electroencephalographic (EEG; bottom traces) recordings. Wakefulness (W) is characterized by low amplitude, desynchronized EEG and sustained EMG activity, SWS by high-voltage slow oscillations in the EEG associated with weak EMG activity, and PS is characterized by pronounced theta rhythm and a complete loss of muscle tone. Dopamine neurons firing switched from irregular spiking with few doublets during wakefulness and SWS to a pronounced bursting pattern with many spikes of decreasing amplitude during PS and feeding. Note the lack of modification of firing during the phasic EMG activation during wakefulness. (c, d) Represent the bursting activity (expressed as percentage of spikes fired in bursts) of 17 neurons recorded across all the three vigilance states (c) and II neurons recorded before and during the consumption of palatable food (d). Note that bursting increased during PS and feeding across the entire population of dopamine neurons. No statistical difference was observed between $\mathrm{W}$ and SWS using t-test for paired values.

triphasic spikes (Figure 1a). Both raw data and a triple Gaussian fit showed a clear separation of short and long action potential durations at $2 \mathrm{~ms}$. Therefore, cells with spike duration $>2 \mathrm{~ms}$ were considered as dopamine cells.

\section{VTA Dopamine Neuronal Activity during the Sleep-Wake Cycle}

Among 94 dopamine neurons recorded, 84 were recorded together with EEG and EMG recordings allowing a good sleep-wake cycle monitoring. Among these, 68 were recorded during wake (W), 52 during SWS, and 25 during PS. The activity of one of the 17 cells recorded across the three vigilances states is illustrated in Figure 2a. Irregular activity was observed during quiet $\mathrm{W}$ and SWS, with rare bursts composed of a few spikes, mostly doublets. In contrast, the activity during PS switched to a pronounced bursting pattern characterized by numerous bursts composed of several spikes of decreasing amplitude.

The mean firing rate increased slightly but not significantly in PS compared to W and SWS (Figure 3a, W: $3.93 \pm 0.16 \mathrm{spikes} / \mathrm{s}, \quad n=68, \quad$ SWS: $3.95 \pm 0.16 \mathrm{spikes} / \mathrm{s}$, $n=52$, PS: $4.63 \pm 0.26$ spikes $/ \mathrm{s}, \quad n=25$, ANOVA, $\mathrm{F}_{2,142}=$ $3.038, p>0.05)$. There was no significant difference in the percentage of spikes fired in bursts between W and SWS. However, there was a highly significant increase in this parameter during PS compared to $\mathrm{W}$ and SWS (Figure 3b,
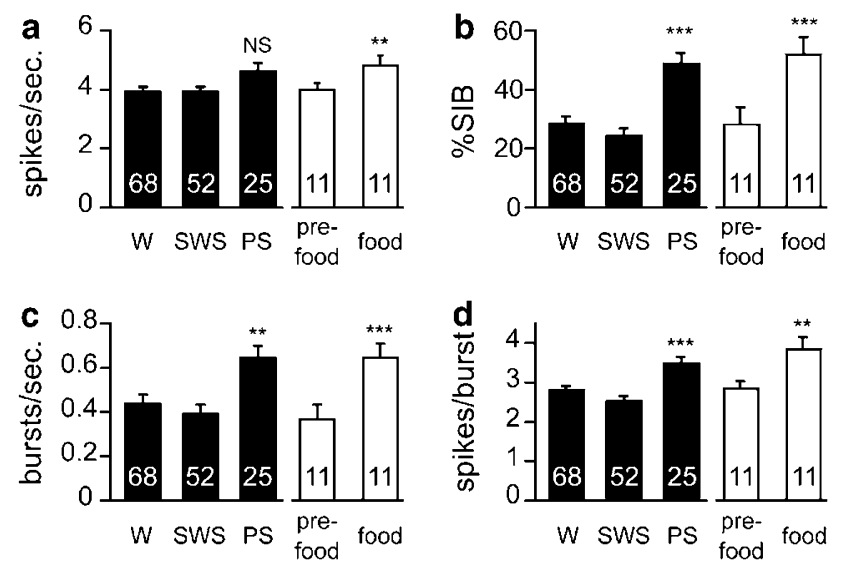

Figure 3 Discharge properties of dopamine neurons during the sleep wake cycle (filled columns) and palatable food consumption (open columns). We measured four complementary parameters: (a) firing rate, (b) the percentage of spikes fired in bursts (\%SIB), (c) the number of bursts per second, and (d) the number of spikes per burst. Note the slight non significant increase in the mean firing rate and the large and highly significant increase in all bursting parameters during PS compared to quiet wakefulness (W) and SWS. This increase was very similar to the activation observed during palatable food consumption (food) as compared to quiet wakefulness preceding food presentation (pre-food). Numbers inside each column indicate the number of analyzed cells. NS $p>0.05$; $* *<<0.0$ l; ***** $p<0.00$ I using appropriate tests (ANOVA, followed by Tukey-Kramer post hoc pair-wise comparisons for vigilance states and Student's t-test for paired values for palatable food consumption). 
$\mathrm{W}: 28.4 \pm 2.6, n=68$, SWS: $24.3 \pm 2.4, n=52$, PS: $48.8 \pm 3.8$, $n=25$, ANOVA, $\mathrm{F}_{2,142}=13.6, p<0.001$, post hoc analysis, $p<0.05$ for PS compared to W and SWS, NS between W and SWS). Importantly, this increase in the percentage of spikes fired in bursts, which was observed in all 17 neurons recorded across the three vigilance states (Figure 2c), gradually appeared 10-20 s before the onset of PS (Figure 4a), was sustained all along the duration of the PS episode (20-200s - see example in Figure 5) and suddenly stopped with the offset of PS (Figure $4 \mathrm{~b}$ ).

Burst characteristics were further analyzed in the three vigilance stages by calculating the burst occurrence, the number of spikes per burst and the intraburst frequency. Both burst occurrence (Figure $3 \mathrm{c}$ ) and the number of spikes per burst (Figure 3d) significantly increased in PS as compared to W and SWS (W: $0.44 \pm 0.04$ bursts/s, $2.81 \pm 0.09$ spike/burst, $n=68$; SWS: $0.39 \pm 0.04$ burst $/ \mathrm{s}$, $2.54 \pm 0.07$ spike/burst, $n=52$; PS: $0.63 \pm 0.06$ bursts/s, $3.49 \pm 0.15$ spike/burst, $n=25, \quad$ ANOVA, $\quad \mathrm{F}_{2,142}=5.558$, $p<0.01$ and $F_{2,142}=19.089, p<0.001$, respectively, Tukey's
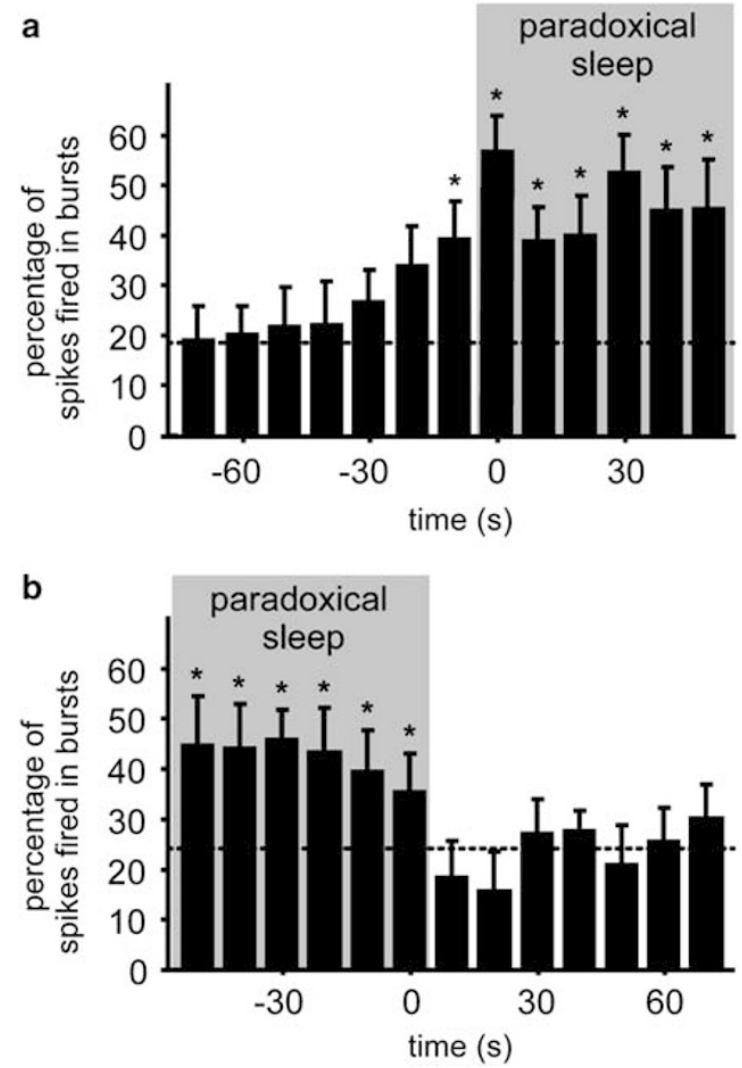

Figure 4 Increase in bursting activity of dopamine neurons anticipates the onset of PS and stops as soon as the animal wakes up from PS. PS onset was defined by the observation of both pronounced theta rythm sychronization on the EEG together with atonia on the EMG, the offset corresponded to awakening characterized by a decrease of theta rhythm and the dispartition of atonia. In all 10 dopamine neurons were recorded during the transitions from SWS to PS (a) and 12 during the transition from PS to W (b). Time zero corresponds to the onset (a) and the offset (b) of PS. Each bar represents the mean percentage of spike in burst measured over $10 \mathrm{~s}$. Dotted lines represent the mean baseline values recorded for this sample of cells during SWS (a) and W (b). Comparison to baseline using $t$-test for paired values shows significant increase in bursting starting before the onset of PS. $* p<0.05$. post hoc analysis, $p<0.05$ for PS compared to W and SWS for both parameters, NS between W and SWS). On the other hand, the mean frequency within bursts remained stable across the sleep-wake cycle (W: $22.1 \pm 0.9$, SWS: $25.1 \pm 1.0$, PS: $22.0 \pm 1.1$ spikes/s, ANOVA, $\left.\mathrm{F}_{2,142}=2.98, p>0.05\right)$. Four neurons never fired a burst during $W$ and one of them never fired a burst during SWS, either.

Averaging of EEG triggered by unit activity did not reveal any correlation between EEG oscillations and neuronal activity in any vigilance state (data not shown).

\section{VTA Dopamine Neuronal Activity during Palatable Food Consumption}

Eleven dopamine neurons were recorded during the consumption of a highly palatable food. As illustrated in Figure 2b, dopamine neurons switched, during food consumption, to a bursting pattern similar to that observed during PS.

There was a slight increase in mean firing rate $(4.82 \pm 0.32$ vs $4.01 \pm 0.21 \mathrm{spike} / \mathrm{s}, \quad p<0.01)$ and a large and highly significant increase in the percentage of spikes fired in bursts $(51.91 \pm 5.75$ vs $28.06 \pm 6.08, p<0.001)$, burst occurrence $(0.64 \pm 0.06$ vs $0.37 \pm 0.07$ bursts $/ s, p<0.001)$, and number of spikes per burst $(3.84 \pm 0.31$ vs $2.84 \pm 0.20$ spike/burst, $p<0.01)$ during food consumption as compared to preceding quiet W (Figure 3 ). The increase in the
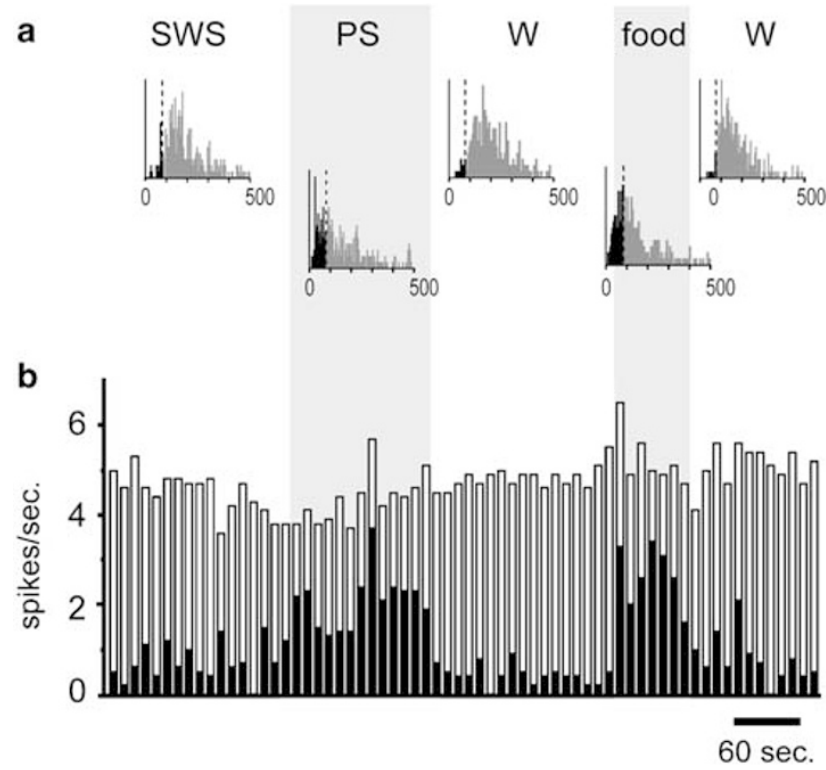

Figure 5 Activity of a dopamine neuron recorded across the sleepwake cycle and during the consumption of palatable food. (a) Inter-spike interval histograms $(I S \mid H)$ for each vigilance state. The switch to a prominent bursting pattern during PS is characterized by an increase of the proportion of short intervals (as an indication, bins corresponding to values $<80 \mathrm{~ms}$ are filled in black on the $I S \mid H)$. (b) Rate-meter representing the tonic and the bursting activity. Each bar represents the mean firing rate recorded over $10 \mathrm{~s}$. The proportion of spikes fired in burst is shown by the filled proportion of the bar. A bar would be fully black if all spikes were fired in burst during the corresponding $10 \mathrm{~s}$ and it would be completely white if no spike spikes were fired in bursts. Note similar increase in burst firing during the entire PS and palatable food consumption (food) periods without clear variation in the mean firing rate, as compared with waking (W) and SWS. 
percentage of spikes fired in bursts was confirmed by the increased proportion of short intervals on comparative interspike interval histograms (Figure 5). It was observed in all recorded neurons (Figure $2 \mathrm{~d}$ ) and lasted throughout the entire period of food consumption (20-120 s), as illustrated in Figure 5. There was no significant variation in the mean frequency within bursts $(21.4 \pm 1.1$ vs $22.7 \pm 1.5 \mathrm{~Hz}$, $p>0.34)$.

There was no significant difference between mean firing rate, or any of the burst parameters between palatable food consumption and PS conditions (Student's $t$-test for unpaired values, firing rate $p>0.67$, percentage of spikes fired in bursts: $p>0.70$, spikes/burst: $p>0.31$, bursts/s: $p>0.98$, intraburst mean frequency: $p>0.48$ ).

\section{DISCUSSION}

Here, we provide the first evidence of a robust increase in bursting activity of VTA dopamine neurons during PS. Dopamine cells were not only more likely to burst during PS, but the bursts also contained more spikes. This increase was similar to the bursting induced by the consumption of palatable food.

A possible difficulty of electrophysiological identification of dopamine neurons has recently been indicated by juxtacellular labeling of VTA non-dopaminergic cells, which did not appear easily distinguishable from dopamine cells by their electrophysiological parameters (Ungless et al, 2004). These authors stressed the necessity for a careful separation of two types of neurons exhibiting short and long triphasic action potentials. However, the shape of action potentials depends on the filtering parameters (Marinelli et al, 2006), thus the criterion used to distinguish different cell types may vary with the use of different filters. By analyzing the action potential duration of each cell recorded in the VTA (Figure 1), we provide evidence that, when using our filtering parameters, the classical and widely used criterion (spike length $>2 \mathrm{~ms}$ ) proposed by Grace and Bunney (1983) allows good discrimination of each cell group, and therefore a good identification of VTA dopamine cells.

The mean firing rate and bursting parameters of VTA dopamine cells recorded in head restrained rat during quiet waking are consistent with those reported previously in freely moving rats during this state (Freeman and Bunney, 1987; Hyland et al, 2002; Kiyatkin and Rebec, 1998; Miller et al, 1983). These values contrast with those reported in a recent study which showed that acute stressful restraint increased dopamine neuron firing rate and bursting activity (Anstrom and Woodward, 2005). This provides evidence that our head restraint procedures, after appropriate habituation, were not associated with undue stress as we have previously shown (Souliere et al, 2000).

We showed for the first time that VTA dopamine neurons switch to a bursting mode of activity for the entire duration of PS episodes. This activation started 10-20s before the onset of PS. This period corresponds to a transition period characterized by an increase in theta rhythm on the EEG, which is not yet accompanied by the muscular atonia (Gottesmann, 1992). The increase in burst firing during PS is consistent with the pioneering observation by Miller et al
(1983) of an increased variance of interspike intervals during PS as compared with SWS. We also confirmed a lack of significant variation in the mean firing rate across vigilance states reported previously in freely moving rats (Miller et al, 1983; Trulson and Preussler, 1984), although there was a tendency to an increase during PS. Such a discrepancy between mean firing rate and bursting activity of VTA dopamine neurons is not surprising since several physiological events known to increase mesocorticolimbic dopamine transmission, such as alerting or rewarding stimuli, induce burst firing but generally fail to alter mean firing rate calculated for relatively long intervals (for review see Kiyatkin, 1995). In addition, an increase in bursting activity without any variation of the mean firing rate has been shown to massively increase extracellular dopamine levels (Floresco et al, 2003). Hence, on the basis of our findings, dopamine should be released at synaptic terminals at VTA outputs. This is also supported by a recent microdialysis study which reported an increase in extracellular dopamine levels within the nucleus accumbens and prefrontal cortex during PS as compared to SWS (Lena et al, 2005). The rather modest increase reported in this study might rely on the difficulty to measure synaptic release of dopamine elicited by bursting activity by using microdialysis without pretreatment with dopamine uptake blockers (Floresco et al, 2003). Thus, although the overall mean firing rate of VTA dopamine neurons does not vary across vigilance states, the large increase in their burst firing most likely underlies a strong activation of the mesocorticolimbic dopamine system during PS episodes, in agreement with the report of an increase in c-fos expression by VTA dopamine cells during PS rebound (Maloney et al, 2002).

Burst firing of dopamine neurons largely depends, in vivo, on glutamatergic NMDA transmission (Chergui et al, 1993; Kuznetsov et al, 2006; Tong et al, 1996) together with cholinergic $\alpha 7$ and $\beta 2$ transmission (Erhardt et al, 2002; Kitai et al, 1999; Mameli-Engvall et al, 2006). The PPN, which sends both glutamatergic and cholinergic inputs to VTA (Omelchenko and Sesack, 2005, 2006), is essential for burst firing of VTA dopamine neurons (Lodge and Grace, 2006a) and elicits dopamine efflux in the rat nucleus accumbens by activation of acetylcholine and glutamate receptors in the VTA (Forster and Blaha, 2000). PPN has also been shown to be highly active during PS (Datta and Siwek, 2002; El Mansari et al, 1989) and it is considered a main PS executive region (Pace-Schott and Hobson, 2002). Thus, it seems likely that the main input responsible for the activation of dopamine cells during PS should arise from the PPN. A recent study has demonstrated that the hippocampus, via its indirect action on dopamine cells, also regulates the intensity of their phasic activation (Lodge and Grace, 2006b). The increase in burst firing during the transitional period, when atonia is not yet triggered but hippocampal theta rhythmic activity is already pronounced, suggests a possible involvement of the reciprocal loop between hippocampus and VTA (Lisman and Grace, 2005) in dopamine cell activation during PS. More experiments will be needed to confirm the possible involvement of both hippocampus and PPN in this phenomenon.

Increase in burst firing before the onset of PS might be compatible with the involvement of dopamine in the generation of this state. However, pharmacological increase 
of dopamine transmission triggered by psychostimulants promotes waking and reduces both SWS and PS (Wisor et $a l, 2001)$ and D1 receptor antagonists increase the amount of PS while D1 agonists suppress it (Trampus et al, 1991). Although sleep is fragmented in Parkinson disease and in animals which received local injections of 6-OHDA in the VTA, dopamine depletion does not induce any clear modification in the time spent in PS over $24 \mathrm{~h}$ (Lai and Siegel, 2003; Sakata et al, 2002). Therefore, it is unlikely that VTA dopamine cells participate in generating or maintaining PS. However, dopamine has been shown to increase theta rhythm in the hippocampus via the activation of D1/ D5 receptors in the medial septum (Fitch et al, 2006; Miura et al, 1987) and injections of 6-OHDA in the VTA decrease the power and frequency of theta rhythm observed during PS (Sei et al, 1999). Thus, although there is no evidence of any involvement of dopamine in the generation of PS, it most likely plays a role in modulating theta rhythm in the hippocampus during PS.

A possibility concerning the functional role of dopaminergic activation during PS could be that these cells are similarly activated by salient rewarding events as is the case during waking, except that the salient events are internally generated. In most studies reporting burst firing of dopamine neurons in response to reward or salient stimuli, the duration of stimuli is comparatively short, thus activations of dopamine cells are typically composed of only one time-locked burst (Dommett et al, 2005; Ungless et al, 2004, see also Schultz, 2002 for review). This form of activation is different from the sustained bursting that we observed in PS. Indeed, here we show that the consumption of palatable food that lasted few minutes led to a sustained increase in bursting, similar to what was observed during PS. This latter observation is in agreement with fast scan cyclic voltammetry experiments that show a sustained phasic release of dopamine in nucleus accumbens during sucrose consumption (Roitman et al, 2004). This observation constitutes, to our knowledge, the first electrophysiological observation of such a long lasting activation of burst firing which may underlie the increase in dopamine levels reported during various behaviors such as feeding, reward, punishment, or sex (Schultz, 2002). The similarity between dopaminergic activity observed during PS and food consumption suggests that, even if sensory thresholds were high and the animal was not perceiving external stimuli, neuronal reactivations occurring during PS, throughout the brain (Louie and Wilson, 2001; Maquet et al, 2000; Peigneux et al, 2003; Ribeiro and Nicolelis, 2004), could underlie the perception of internally generated rewarding or at least salient experiences.

Many studies have shown that dopamine is involved in synaptic plasticity in nucleus accumbens, cortex, and hippocampus (Sajikumar and Frey, 2004, for review see Jay, 2003; Lisman and Grace, 2005). Dopamine promotes both LTP in the hippocampus and long-term memory (Frey et al, 1991; Li et al, 2003; Morris et al, 2003; Swanson-Park et al, 1999) via the activation of D1/D5 receptors, which activate the cAMP/CREB pathway (Bernabeu et al, 1997; Blitzer et al, 1998; Otmakhova and Lisman, 1996) and leads to the activation of zif-268 (Bozon et al, 2003). Zif-268 is an immediate early gene necessary for both late LTP and longterm memory (Barco et al, 2002; Bozon et al, 2003; Jones et al, 2001), which triggers the synthesis of proteins involved in synaptic function such as synapsins (Rosahl et al, 1995; Thiel et al, 1994). Zif-268 has been shown to be upregulated during PS following exposure to enriched environment by mechanisms yet to be determined (Ribeiro et al, 1999). Others have hypothesized that Zif-268 expression during PS and memory consolidation could be triggered via cholinergic modulation since the ascending cholinergic system (arising from PPN and basal forebrain) was thought to be the only neuromodulatory system activated during PS (Jones, 2005; Pace-Schott and Hobson, 2002). We propose that, as it does during W, dopamine could participate in synaptic plasticity in the hippocampus and long-term memory consolidation occurring during PS (Walker et al, 2003, Walker and Stickgold, 2004, Walker and Stickgold, 2006) via its action on D1/D5, cAMP, CREB, and finally zif-268 triggering protein synthesis.

PS has also been associated with the experience of vivid dreaming (Aserinsky and Kleitman, 1953, for review see Hobson and Pace-Schott, 2002). Cessation of dream recall has been documented in Parkinson disease (Sandyk, 1997) while L-DOPA therapy enhances vivid dream recall (Hobson and Pace-Schott, 1999). In addition, patients with lesions of dopamine related cortical areas such as ventromedial prefrontal lobe also have deficits in dream recall (Solms, 2000). Although there is still debate concerning the fact that dopamine could either be required for dreaming or for recall, these observations led Solms to hypothesize that dreaming is not triggered by PS but by activation of the mesolimbic dopamine system that should occur during PS (Solms, 2000). The main objection to such a theory was the lack of any clear evidence of an increase in the activity of the mesolimbic dopamine system. As we now provide such evidence, perhaps it is time to reconsider this theory and speculate that the activation of the dopamine system, we report here could participate in dreaming occurring during PS.

In summary, our results constitute the first electrophysiological evidence of an increased activity of VTA dopamine neurons during PS. This observation challenges the usual thought that dopamine neurons are the only aminergic group not involved in sleep physiology. It seems unlikely that dopamine could be involved in PS generation. However, as during waking, dopamine system could be activated by internally generated rewarding or salient stimuli and participate to the modulation of hippocampal activity and plasticity and, thus, to memory processing. In the light of these results, physiological and cognitive events characteristic of PS should no longer be considered to result from cholinergic neuromodulation alone, but rather from a combined action of high cholinergic and dopaminergic states.

\section{ACKNOWLEDGEMENTS}

Lionel Dahan and Nicolas Vautrelle were recipients of fellowships from MILDT (grant MSU, 2001) and 'Région Rhône-Alpes' (Grant 'Emergence' 2001) respectively. This work was also supported by Université Claude BernardLyon1, INSERM, MENRT (ACI, Grant 0220411); Fondation de France (Grant 2002-011947) and NIH (Grant MH62525). 
We thank C Peyron, E Pace-Schott, V Coizet and P Redgrave for their comments on the manuscript, E Duboeuf, $\mathrm{T}$ Duffau, F Lorent and D Vannereau for their technical assistance.

\section{REFERENCES}

Anstrom KK, Woodward DJ (2005). Restraint increases dopaminergic burst firing in awake rats. Neuropsychopharmacology 30: $1832-1840$.

Aserinsky E, Kleitman N (1953). Regularly occurring periods of eye motility, and concomitant phenomena, during sleep. Science 118: 273-274.

Barco A, Alarcon JM, Kandel ER (2002). Expression of constitutively active CREB protein facilitates the late phase of long-term potentiation by enhancing synaptic capture. Cell 108: 689-703.

Bassareo V, Di Chiara G (1997). Differential influence of associative and nonassociative learning mechanisms on the responsiveness of prefrontal and accumbal dopamine transmission to food stimuli in rats fed ad libitum. J Neurosci 17: 851-861.

Bernabeu R, Bevilaqua L, Ardenghi P, Bromberg E, Schmitz P, Bianchin $\mathrm{M}$ et al (1997). Involvement of hippocampal cAMP/ cAMP-dependent protein kinase signaling pathways in a late memory consolidation phase of aversively motivated learning in rats. Proc Natl Acad Sci USA 94: 7041-7046.

Blitzer RD, Connor JH, Brown GP, Wong T, Shenolikar S, Iyengar $\mathrm{R}$ et al (1998). Gating of CaMKII by cAMP-regulated protein phosphatase activity during LTP. Science 280: 1940-1942.

Bozon B, Kelly A, Josselyn SA, Silva AJ, Davis S, Laroche S (2003). MAPK, CREB and zif268 are all required for the consolidation of recognition memory. Philos Trans $R$ Soc Lond B Biol Sci 358: 805-814.

Chergui K, Charlety PJ, Akaoka H, Saunier CF, Brunet JL, Buda M et al (1993). Tonic activation of NMDA receptors causes spontaneous burst discharge of rat midbrain dopamine neurons in vivo. Eur J Neurosci 5: 137-144.

Datta S, Siwek DF (2002). Single cell activity patterns of pedunculopontine tegmentum neurons across the sleep-wake cycle in the freely moving rats. $J$ Neurosci Res 70: 611-621.

Dommett E, Coizet V, Blaha CD, Martindale J, Lefebvre V, Walton $\mathrm{N}$ et al (2005). How visual stimuli activate dopaminergic neurons at short latency. Science 307: 1476-1479.

El Mansari M, Sakai K, Jouvet M (1989). Unitary characteristics of presumptive cholinergic tegmental neurons during the sleepwaking cycle in freely moving cats. Exp Brain Res 76: 519-529.

Erhardt S, Schwieler L, Engberg G (2002). Excitatory and inhibitory responses of dopamine neurons in the ventral tegmental area to nicotine. Synapse 43: 227-237.

Fitch TE, Sahr RN, Eastwood BJ, Zhou FC, Yang CR (2006). Dopamine D1/5 receptor modulation of firing rate and bidirectional theta burst firing in medial septal/vertical limb of diagonal band neurons in vivo. J Neurophysiol 95: 2808-2820.

Fitt AD, Gonzalez G (2006). Fluid mechanics of the human eye: aqueous humour flow in the anterior chamber. Bull Math Biol 68: $53-71$.

Floresco SB, West AR, Ash B, Moore H, Grace AA (2003). Afferent modulation of dopamine neuron firing differentially regulates tonic and phasic dopamine transmission. Nat Neurosci 6: 968-973.

Forster GL, Blaha CD (2000). Laterodorsal tegmental stimulation elicits dopamine efflux in the rat nucleus accumbens by activation of acetylcholine and glutamate receptors in the ventral tegmental area. Eur J Neurosci 12: 3596-3604.

Freeman AS, Bunney BS (1987). Activity of A9 and A10 dopaminergic neurons in unrestrained rats: further charac- terization and effects of apomorphine and cholecystokinin. Brain Res 405: 46-55.

Frey U, Matthies H, Reymann KG, Matthies H (1991). The effect of dopaminergic D1 receptor blockade during tetanization on the expression of long-term potentiation in the rat CA1 region in vitro. Neurosci Lett 129: 111-114.

Gonon FG (1988). Nonlinear relationship between impulse flow and dopamine released by rat midbrain dopaminergic neurons as studied by in vivo electrochemistry. Neuroscience 24: 19-28.

Gottesmann C (1992). Detection of seven sleep-waking stages in the rat. Neurosci Biobehav Rev 16: 31-38.

Grace AA, Bunney BS (1983). Intracellular and extracellular electrophysiology of nigral dopaminergic neurons - 1. Identification and characterization. Neuroscience 10: 301-315.

Grace AA, Bunney BS (1984). The control of firing pattern in nigral dopamine neurons: burst firing. J Neurosci 4: 2877-2890.

Hobson JA, Pace-Schott EF (1999). Enhancement of dreaming by L-DOPA. Neuropsychoanalysis 1: 206-224.

Hobson JA, Pace-Schott EF (2002). The cognitive neuroscience of sleep: neuronal systems, consciousness and learning. Nat Rev Neurosci 3: 679-693.

Hyland BI, Reynolds JN, Hay J, Perk CG, Miller R (2002). Firing modes of midbrain dopamine cells in the freely moving rat. Neuroscience 114: 475-492.

Jay TM (2003). Dopamine: a potential substrate for synaptic plasticity and memory mechanisms. Prog Neurobiol 69: 375-390.

Jones BE (2005). From waking to sleeping: neuronal and chemical substrates. Trends Pharmacol Sci 26: 578-586.

Jones MW, Errington ML, French PJ, Fine A, Bliss TV, Garel S et al (2001). A requirement for the immediate early gene Zif268 in the expression of late LTP and long-term memories. Nat Neurosci 4: 289-296.

Jouvet M (1967). The states of sleep. Sci Am 216: 62-68 passim.

Kilpatrick MR, Rooney MB, Michael DJ, Wightman RM (2000). Extracellular dopamine dynamics in rat caudate-putamen during experimenter-delivered and intracranial self-stimulation. Neuroscience 96: 697-706.

Kitai ST, Shepard PD, Callaway JC, Scroggs R (1999). Afferent modulation of dopamine neuron firing patterns. Curr Opin Neurobiol 9: 690-697.

Kiyatkin EA (1995). Functional significance of mesolimbic dopamine. Neurosci Biobehav Rev 19: 573-598.

Kiyatkin EA, Rebec GV (1998). Heterogeneity of ventral tegmental area neurons: single-unit recording and iontophoresis in awake, unrestrained rats. Neuroscience 85: 1285-1309.

Kuznetsov AS, Kopell NJ, Wilson CJ (2006). Transient highfrequency firing in a coupled-oscillator model of the mesencephalic dopaminergic neuron. J Neurophysiol 95: 932-947.

Lai YY, Siegel JM (2003). Physiological and anatomical link between Parkinson-like disease and REM sleep behavior disorder. Mol Neurobiol 27: 137-152.

Legault M, Wise RA (2001). Novelty-evoked elevations of nucleus accumbens dopamine: dependence on impulse flow from the ventral subiculum and glutamatergic neurotransmission in the ventral tegmental area. Eur J Neurosci 13: 819-828.

Lena I, Parrot S, Deschaux O, Muffat-Joly S, Sauvinet V, Renaud B et al (2005). Variations in extracellular levels of dopamine, noradrenaline, glutamate, and aspartate across the sleep-wake cycle in the medial prefrontal cortex and nucleus accumbens of freely moving rats. J Neurosci Res 81: 891-899.

Li S, Cullen WK, Anwyl R, Rowan MJ (2003). Dopamine-dependent facilitation of LTP induction in hippocampal CA1 by exposure to spatial novelty. Nat Neurosci 6: 526-531.

Lisman JE, Grace AA (2005). The hippocampal-VTA loop: controlling the entry of information into long-term memory. Neuron 46: 703-713. 
Ljungberg T, Apicella P, Schultz W (1992). Responses of monkey dopamine neurons during learning of behavioral reactions. J Neurophysiol 67: 145-163.

Lodge DJ, Grace AA (2006a). The laterodorsal tegmentum is essential for burst firing of ventral tegmental area dopamine neurons. Proc Natl Acad Sci USA 103: 5167-5172.

Lodge DJ, Grace AA (2006b). The hippocampus modulates dopamine neuron responsivity by regulating the intensity of phasic neuron activation. Neuropsychopharmacology 31: 1356-1361.

Louie K, Wilson MA (2001). Temporally structured replay of awake hippocampal ensemble activity during rapid eye movement sleep. Neuron 29: 145-156.

Maloney KJ, Mainville L, Jones BE (1999). Differential c-Fos expression in cholinergic, monoaminergic, and GABAergic cell groups of the pontomesencephalic tegmentum after paradoxical sleep deprivation and recovery. J Neurosci 19: 3057-3072.

Maloney KJ, Mainville L, Jones BE (2002). c-Fos expression in dopaminergic and GABAergic neurons of the ventral mesencephalic tegmentum after paradoxical sleep deprivation and recovery. Eur J Neurosci 15: 774-778.

Mameli-Engvall M, Evrard A, Pons S, Maskos U, Svensson TH, Changeux JP et al (2006). Hierarchical control of dopamine neuron-firing patterns by nicotinic receptors. Neuron 50: 911-921.

Maquet P, Laureys S, Peigneux P, Fuchs S, Petiau C, Phillips C et al (2000). Experience-dependent changes in cerebral activation during human REM sleep. Nat Neurosci 3: 831-836.

Marinelli M, Rudick CN, Hu XT, White FJ (2006). CNS \& Neurological Disorders-Drug Targets, Vol. 5. pp 79-97.

Miller JD, Farber J, Gatz P, Roffwarg H, German DC (1983). Activity of mesencephalic dopamine and non-dopamine neurons across stages of sleep and waking in the rat. Brain Res 273: 133-141.

Miura Y, Ito T, Kadokawa T (1987). Effects of intraseptally injected dopamine and noradrenaline on hippocampal synchronized theta wave activity in rats. Jpn J Pharmacol 44: 471-479.

Morris RG, Moser EI, Riedel G, Martin SJ, Sandin J, Day M et al (2003). Elements of a neurobiological theory of the hippocampus: the role of activity-dependent synaptic plasticity in memory. Philos Trans $R$ Soc Lond B Biol Sci 358: 773-786.

Omelchenko N, Sesack SR (2005). Laterodorsal tegmental projections to identified cell populations in the rat ventral tegmental area. J Comp Neurol 483: 217-235.

Omelchenko N, Sesack SR (2006). Cholinergic axons in the rat ventral tegmental area synapse preferentially onto mesoaccumbens dopamine neurons. J Comp Neurol 494: 863-875.

Otmakhova NA, Lisman JE (1996). D1/D5 dopamine receptor activation increases the magnitude of early long-term potentiation at CA1 hippocampal synapses. $J$ Neurosci 16: 7478-7486.

Pace-Schott EF, Hobson JA (2002). The neurobiology of sleep: genetics, cellular physiology and subcortical networks. Nat Rev Neurosci 3: 591-605.

Pan WX, Hyland BI (2005). Pedunculopontine tegmental nucleus controls conditioned responses of midbrain dopamine neurons in behaving rats. J Neurosci 25: 4725-4732.

Peigneux P, Laureys S, Fuchs S, Destrebecqz A, Collette F, Delbeuck X et al (2003). Learned material content and acquisition level modulate cerebral reactivation during posttraining rapid-eye-movements sleep. Neuroimage 20: 125-134.

Ribeiro S, Goyal V, Mello CV, Pavlides C (1999). Brain gene expression during REM sleep depends on prior waking experience. Learn Mem 6: 500-508.

Ribeiro S, Nicolelis MA (2004). Reverberation, storage, and postsynaptic propagation of memories during sleep. Learn Mem 11: 686-696.
Roitman MF, Stuber GD, Phillips PE, Wightman RM, Carelli RM (2004). Dopamine operates as a subsecond modulator of food seeking. J Neurosci 24: 1265-1271.

Rosahl TW, Spillane D, Missler M, Herz J, Selig DK, Wolff JR et al (1995). Essential functions of synapsins I and II in synaptic vesicle regulation. Nature 375: 488-493.

Sajikumar S, Frey JU (2004). Late-associativity, synaptic tagging, and the role of dopamine during LTP and LTD. Neurobiol Learn Mem 82: 12-25.

Sakata M, Sei H, Toida K, Fujihara H, Urushihara R, Morita Y (2002). Mesolimbic dopaminergic system is involved in diurnal blood pressure regulation. Brain Res 928: 194-201.

Sandyk R (1997). Treatment with weak electromagnetic fields restores dream recall in a parkinsonian patient. Int J Neurosci 90: 75-86.

Schultz W (2002). Getting formal with dopamine and reward. Neuron 36: 241-263.

Schultz W, Apicella P, Ljungberg T (1993). Responses of monkey dopamine neurons to reward and conditioned stimuli during successive steps of learning a delayed response task. J Neurosci 13: 900-913.

Sei H, Ikemoto K, Arai R, Morita Y (1999). Injection of 6hydroxydopamine into the ventral tegmental area suppresses the increase in arterial pressure during REM sleep in the rat. Sleep Res Online 2: 1-6.

Smith C, Rose GM (1996). Evidence for a paradoxical sleep window for place learning in the Morris water maze. Physiol Behav 59: 93-97.

Smith C, Rose GM (1997). Posttraining paradoxical sleep in rats is increased after spatial learning in the Morris water maze. Behav Neurosci 111: 1197-1204.

Solms M (2000). Dreaming and REM sleep are controlled by different brain mechanisms. Behav Brain Sci 23: 843-850; discussion 904-1121.

Souliere F, Urbain N, Gervasoni D, Schmitt P, Guillemort C, Fort P et al (2000). Single-unit and polygraphic recordings associated with systemic or local pharmacology: a multi-purpose stereotaxic approach for the awake, anaesthetic-free, and headrestrained rat. J Neurosci Res 61: 88-100.

Steinfels GF, Heym J, Strecker RE, Jacobs BL (1983). Behavioral correlates of dopaminergic unit activity in freely moving cats. Brain Res 258: 217-228.

Stickgold R, Hobson JA, Fosse R, Fosse M (2001). Sleep, learning, and dreams: off-line memory reprocessing. Science 294: 10521057.

Stickgold R, Walker MP (2005). Sleep and memory: the ongoing debate. Sleep 28: 1225-1227.

Swanson-Park JL, Coussens CM, Mason-Parker SE, Raymond CR, Hargreaves EL, Dragunow M et al (1999). A double dissociation within the hippocampus of dopamine D1/D5 receptor and betaadrenergic receptor contributions to the persistence of longterm potentiation. Neuroscience 92: 485-497.

Thiel G, Schoch S, Petersohn D (1994). Regulation of synapsin I gene expression by the zinc finger transcription factor zif268/ egr-1. J Biol Chem 269: 15294-15301.

Tong ZY, Overton PG, Clark D (1996). Antagonism of NMDA receptors but not AMPA/kainate receptors blocks bursting in dopaminergic neurons induced by electrical stimulation of the prefrontal cortex. J Neural Transm 103: 889-904.

Trampus M, Ferri N, Monopoli A, Ongini E (1991). The dopamine D1 receptor is involved in the regulation of REM sleep in the rat. Eur J Pharmacol 194: 189-194.

Trulson ME, Preussler DW (1984). Dopamine-containing ventral tegmental area neurons in freely moving cats: activity during the sleep-waking cycle and effects of stress. Exp Neurol 83: 367-377.

Ungless MA (2004). Dopamine: the salient issue. Trends Neurosci 27: 702-706. 
Ungless MA, Magill PJ, Bolam JP (2004). Uniform inhibition of dopamine neurons in the ventral tegmental area by aversive stimuli. Science 303: 2040-2042.

Urbain N, Creamer K, Debonnel G (2006). Electrophysiological diversity of the dorsal raphe cells across the sleep-wake cycle of the rat. J Physiol 573: 679-695.

Urbain N, Gervasoni D, Souliere F, Lobo L, Rentero N, Windels F et al (2000). Unrelated course of subthalamic nucleus and globus pallidus neuronal activities across vigilance states in the rat. Eur J Neurosci 12: 3361-3374.

Urbain N, Rentero N, Gervasoni D, Renaud B, Chouvet G (2002). The switch of subthalamic neurons from an irregular to a bursting pattern does not solely depend on their GABAergic inputs in the anesthetic-free rat. J Neurosci 22: 8665-8675.

Urbain N, Vautrelle N, Dahan L, Savasta M, Chouvet G (2004). Glutamatergic-receptors blockade does not regularize the slow wave sleep bursty pattern of subthalamic neurons. Eur J Neurosci 20: $392-402$.

Venton BJ, Zhang H, Garris PA, Phillips PE, Sulzer D, Wightman RM (2003). Real-time decoding of dopamine concentration changes in the caudate-putamen during tonic and phasic firing. J Neurochem 87: 1284-1295.
Verret L, Leger L, Fort P, Luppi PH (2005). Cholinergic and noncholinergic brainstem neurons expressing Fos after paradoxical (REM) sleep deprivation and recovery. Eur J Neurosci 21: 2488-2504.

Walker MP, Brakefield T, Hobson JA, Stickgold R (2003). Dissociable stages of human memory consolidation and reconsolidation. Nature 425: 616-620.

Walker MP, Stickgold R (2004). Sleep-dependent learning and memory consolidation. Neuron 44: 121-133.

Walker MP, Stickgold R (2006). Sleep, memory, and plasticity. Annu Rev Psychol 57: 139-166.

Westerink BH, Kwint HF, de Vries JB (1997). Eatinginduced dopamine release from mesolimbic neurons is mediated by NMDA receptors in the ventral tegmental area: a dual-probe microdialysis study. J Neurochem 69: 662-668.

Wightman RM, Robinson DL (2002). Transient changes in mesolimbic dopamine and their association with 'reward'. I Neurochem 82: 721-735.

Wisor JP, Nishino S, Sora I, Uhl GH, Mignot E, Edgar DM (2001). Dopaminergic role in stimulant-induced wakefulness. J Neurosci 21: 1787-1794. 